\title{
HPLC Method Optimization and Validation for Determination of Lycopene in Tomato (Lycopersicon esculentum, Mill.) Fruits
}

\author{
Wondu Garoma Berra \\ Food and Bioprocess Technology Program, College of Engineering and Technology, \\ Wollega University, Post Box No: 395, Nekemte, Ethiopia
}

\begin{tabular}{|c|c|}
\hline Abstract & Article Information \\
\hline \multirow{13}{*}{$\begin{array}{l}\text { The aim of this work was to develop efficient and accurate protocol that can } \\
\text { measure lycopene in tomato. A total of ten tomato varieties loose and cluster types } \\
\text { were selected for the study. All the tomatoes were harvested at commercial } \\
\text { ripening stage and prepared after } 3 \text { days of storage at } 18^{\circ} \mathrm{C} \text { and relative humidity } \\
\text { (RH) of } 80 \% \text {. For analysis purpose each tomato was cut, quartered, chopped and } \\
\text { frozen in liquid nitrogen and then subjected to grinding. The finely ground tomato } \\
\text { samples were immediately filled into air-tight plastic tube and stored in freezer (-80 } \\
{ }^{\circ} \mathrm{C} \text { ) for about two weeks. Finally, the tomato samples were prepared in different } \\
\text { composition of extraction solvent before subjected to HPLC analysis. Mobile phase } \\
\text { composition Acetonitrile/Methanol ( } 50: 50, \mathrm{v} / \mathrm{v}) \text { added with Triethylamine } 9 \mu \mathrm{M} \text {; } \\
\text { extraction solvents hexane/acetone/ethanol }(50: 25: 25 \mathrm{v} / \mathrm{v} / \mathrm{v}) \text {; re-dissolving residue } \\
\text { in Tetrahydrofuran, followed Acetonitrile/Methanol }(15: 30: 55 \text {, v/v/v); flow rate } 0.6 \\
\mathrm{mL} / \mathrm{min} \text { and } \lambda \text { detection near to } 472 \mathrm{~nm} \text { were showed most suitable for lycopene } \\
\text { determination in tomato, achieving best characteristic spectral profile with precision } \\
(\mathrm{RSD}<15) \text {, accuracy and recovery ( } \geq 81.7 \%) \text {, and sensitive detection limit }(0.0156 \\
\mu \mathrm{g} / \mathrm{mL}) \text { within separation of } \sim 21 \text { minutes. The result showed that HPLC is most } \\
\text { accepted and efficient method for determining lycopene in tomato. }\end{array}$} & Article History: \\
\hline & Received : 14-07-2012 \\
\hline & Revised : :08-12-2012 \\
\hline & Accepted : 19-12-2012 \\
\hline & Keywords: \\
\hline & Tomato \\
\hline & Lycopene \\
\hline & Optimizing method \\
\hline & HPLC \\
\hline & ${ }^{*}$ Corresponding Author: \\
\hline & Wondu Garoma Berra \\
\hline & E-mail: \\
\hline & woundugaroma@gmail.com \\
\hline
\end{tabular}

\section{INTRODUCTION}

Lycopene is the most abundant carotenoid pigment principally responsible for the characteristic deep-red color of ripe tomato fruits and tomato products. Recently, a lot of attention has been paid to its biological and physicochemical properties, especially related to its effect as a natural antioxidant (Ananthanarayan and Choudhari, 2007; Barba et al., 2006; Qiu et al., 2006; Rao, 2007; Maguer and Shi, 2000), with a singlet oxygen physical quenching rate constant almost twice as high as that of $\beta$-carotene and more than ten times higher than that of $\alpha$-tocopherol (DiMascio et al., 1989; Ali and Rao, 2007; Pol et al., 2004; Shi et al., 2003).

Lycopene, having a high neutraceutical value, has a wide use in pharmaceutical, food, feed, and cosmetic industries (Barba et al., 2006; Maguer and Shi, 2000). Reports from Ananthanarayan and Choudhari (2007) and Maguer and Shi (2000) indicate the commercial importance of lycopene as natural color ingredient in food formulations from the widespread use of tomato paste as a colorant. As a result, industrial production of lycopene from tomatoes is highly demanded by pharmaceutical companies and for functional food development.

According to Hart and Scott, (1995), tomatoes normally contain about 3 to $5 \mathrm{mg}$ lycopene per $100 \mathrm{~g}$ of raw material, although concentration varies depending on tomato products (Bicanic et al., 2005), ripening process and storage temperature (Barrett and Garcia, 2006). For example, and temperature higher than $32.2^{\circ} \mathrm{C}$ during the growing season results in smaller lycopene concentrations in tomatoes (Barrett and Garcia, 2006). 
Wondu Garoma Berra

Today, a number of analytical procedures have been developed and applied for the determination of antioxidants in fresh tomato and processed tomato products (Gomez-Romero et al., 2007) in a destructive and non-destructive way including electronic tongue (Rudnitskaya et al., 2001), colorimeter, electronic nose (Berna et al., 2002), the acoustic firmness sensor (AFS), near infrared spectroscopy (NIR) (Peirs et al., 2003; Yong et al., 2005; Baranska et al., 2006), nuclear magnetic resonance (NMR) (Gladdeny and Alexanderz, 1996), NIR-FT-Raman spectroscopy (Schulz et al., 2005), Fourier transform infrared spectroscopy (FTIR), hyperspectral imaging (Berna, 2006), etc.

However, the analytical methods used for lycopene are rather complicated (Barba et al., 2006), and not all analytical methods available for carotenoid analysis in food products are suitable for lycopene rich foods due to its low solubility and interference with mobile phase in some of the solvents employed. Furthermore, the instability of lycopene during processes of extraction, handling, and elimination of organic solvents makes the sample preparation for lycopene an extremely delicate task, often requiring successive and complex procedures to ensure that all the carotenoids are extracted (Barba et al., 2006; Maguer and Shi, 2000; Xu et al., 2006).

Therefore, optimization of the existing methodologies of extraction/separation and the necessity for a reliable and rapid analysis method for lycopene in tomatoes was importantly considered in this work.

\section{MATERIALS AND METHODS}

\section{Experimental Design and Plant Materials}

A total of ten tomato varieties, 5 loose cultivars (Growdena, Brodena, DRW 75-93, Admiro and Excelsior), and 5 cluster type (Tricia, Clotilde, Bonaparte, Plaisance and Dirk) were selected and harvested at commercial ripening for the study. These tomato varieties were obtained from two experimental gardens in Belgium and prepared after 3 days storage at $18^{\circ} \mathrm{C}$ and $80 \%$ $\mathrm{RH}$. For analysis tomatoes were cut, quartered, chopped and frozen in liquid nitrogen, then subjected to grinding. The finely ground tomato samples were immediately filled into air-tight 15 $\mathrm{mL}$ plastic tube and stored in freezer $\left(-80^{\circ} \mathrm{C}\right)$ for about two weeks before HPLC analysis.
Sci. Technol. Arts Res. J., Oct-Dec 2012, 1(4):14-26

\section{HPLC Analysis of Lycopene}

\section{Instrumentation}

The HPLC apparatus (Hewlett Packard, series 1100) was equipped with a quaternary Isopump Exchange System (G1310A), Degasser (G1379A), ALS autosampler (G1329A), ALS Therm thermostat (G1330B) column heater and a Thermo Separation Spectra Series UV/Visible diode-array detector (G1315A). Data processing and analysis were carried out using HP Agilent ChemStation software (Agilent Company). The column used for separation was Prevail $\mathrm{C} 185 \mu$ ( $250 \times 3 \mathrm{~mm}$ i.d., Alltech), coupled to Prevail C18 $5 \mu(7.5 \times 2.1 \mathrm{~mm}$ i.d., Altech) guard column. A Thermo spectronic model Genesys 10 UV (Rochester, NY, USA) spectrophotometer was routinely used for measuring absorbance of the working standard solutions.

\section{Chemicals/Reagents and Standards}

Standards of lycopene from tomato (purity $99 \%$ ), and $\beta$-carotene (type II: Synthetic $\geq 95 \%$ ) were obtained from Sigma Company (St. Louis, MO, USA), while $\beta$-apo-8'-carotenal (8'-apo- $\beta, \varphi$ caroten-8'-al) was purchased from Fluka Company. HPLC grade solvents were supplied by ACROS organics in the case of methanol $(\mathrm{MeOH}), \mathrm{n}$-hexane and Tetrahydrofuran (THF, stabilized with $0.025 \%$ butylated hydroxytoluene, $\mathrm{BHT}$ ). Ethanol absolute and Chloroform were obtained from VWR Company. Acetonitrile (ACN, HPLC gradient grade) was from Fisher Scientific, Acetone from Chemlab and Triethylamine (TEA) from Fluka. High-purity oxygen-free nitrogen gas (purity $>99 \%$ ) was obtained from Air products (MAP gasses, Belgium). De-mineralized water was prepared regularly supplied to the laboratory through pipeline.

\section{Preparation of Standard Solutions}

\section{Lycopene}

The trans-lycopene (all-E'-lycopene) standard solution was prepared by diluting $1 \mathrm{mg}$ commercial lycopene standard from tomato with hexane to desired concentration and the solutions were transferred to a volumetric flask. To avoid degradation, lycopene solution was divided into $1.5 \mathrm{~mL}$ aliquots in an air-tight screwtopped brown glass vials, dried under nitrogen and stored at $-20^{\circ} \mathrm{C}$. Individual stock standard solutions were freshly prepared every day adding a suitable volume of hexane to the vials containing lycopene standard and mixing until complete dissolution. Then, the concentration was determined using Beer's law $(A=\varepsilon b c)$ from its extinction coefficient $\left(E_{1 \mathrm{~cm}}^{1 \%} 3450\right.$ in hexane at $472 \mathrm{~nm}$, Arroyave et al., 1982). Then, the 
Wondu Garoma Berra

concentrations of the standard solutions were calculated as below.

$$
\boldsymbol{C}_{\text {all-E'-Lycopene }}[\mathrm{mg} / L]=\frac{\text { Absorption } \times 10^{4}}{3450}
$$

Individual working solutions were prepared from stock solutions each day by evaporating an aliquot with nitrogen and making to desired volume and concentration with re-dissolution solvents. Efficient solubility of the residue was achieved by using re-dissolving solvent composition THF followed by $\mathrm{ACN} / \mathrm{MeOH}$ $(15: 30: 55, v / v / v)$.

\section{$\beta$-Carotene}

A working solution of $\beta$-carotene was prepared by diluting a stock solution of $\beta$-carotene with hexane to desired concentration in a similar way as standard lycopene preparation, while considering its extinction coefficient 2590 in hexane at $450 \mathrm{~nm}$.

\section{$\beta$-Apo-8'-Carotenal (Trans)}

According to Hart and Scott (1995), the internal standard $\beta$-apo- $8^{\circ}$-carotenal was used to assess losses during extraction procedure. A working solution of $\beta$-apo-8'-carotenal was prepared directly in solvent composition of THF followed by ACN/MeOH (15:30:55 v/v/v) and used as stock solution for further dilution to obtain the desired concentration for detection at $450 \mathrm{~nm}$.

\section{Sample Preparation}

Lycopene extraction from tomato was based on modifications and optimization of Barba et al. (2006) method, with solvents mixtures of hexane/ acetone/ethanol (50:25:25, v/v/v) for extraction. Sample containing between 1.5-2.5 g of tomato juice was precisely weighed into a $250 \mathrm{~mL}$ Erlenmeyer flask, tightly wrapped in aluminum foil to protect it from light and then mixed with $100 \mathrm{~mL}$ of extraction solvent. The mixture was stirred on a magnetic stirring plate during $30 \mathrm{~min}$. To the extract, $15 \mathrm{~mL}$ of de-mineralized water was added and mechanically agitated. The solution was subsequently separated into distinct phases of polar and non-polar layers. From lycopenebearing upper hexane layer, $10 \mathrm{~mL}$ was placed in a round-bottomed flask and dried in rotary evaporator $\left(\sim 34^{\circ} \mathrm{C}\right)$. Different compositions of solvents (THF/ACN/MeOH) were assayed for redissolution of the dry extract: (1) THF/ACN/MeOH (15:30:55, v/v/v), (2) THF/ACN/MeOH (15:55:30, $\mathrm{v} / \mathrm{v} / \mathrm{v}$ ) and, (3) dissolving in THF and then ACN/MeOH followed (15:30:55, v/v/v). In all the solvents containing Methanol and Acetonitrile, ultrasonic agitation for few minutes was used to
Sci. Technol. Arts Res. J., Oct-Dec 2012, 1(4):14-26

make sure that the solvents were mixed homogeneously.

The lycopene residue was dissolved to final volume of $8 \mathrm{~mL}$ with solvent system 3 for HPLC analysis. Due to variations in lycopene content among tomato samples, also other volumes i.e., $4 \mathrm{~mL}$ and $16 \mathrm{~mL}$ have been considered and tested to keep quantification within optimal calibration range. The final solution was filtered through 0.45 $\mu \mathrm{m}$ membrane filters (13 $\mathrm{mm}$ i.d., Altech) and then $20 \mu \mathrm{L}$ was injected for HPLC analysis.

\section{Chromatographic Conditions}

Tomato extracts were analysed for lycopene content by separation followed by quantitative determination using reversed-phase HPLC system consisting of UV/visible diode-array detector separation module, auto-injector, and column temperature regulator. The $\mathrm{C} 18$ column was then conditioned with the elution solvent at flow rate of $0.6 \mathrm{~mL} / \mathrm{min}$ with detection at $472 \mathrm{~nm}$. Other flow rates including 0.9 and $1.5 \mathrm{~mL} / \mathrm{min}$ have also been tested. Based on Barba et al. (2006) and www.alltech.be, separation of carotenoids was attempted isocratically using various compositions of $\mathrm{MeOH}$ and $\mathrm{ACN}$ as mobile phase: (1) MeOH /ACN (90:10, v/v) added with $9 \mu \mathrm{M}$ TEA, (2) ACN/ $\mathrm{MeOH}(75: 25, \mathrm{v} / \mathrm{v})$ added with $9 \mu \mathrm{M}$ TEA and (3) ACN/MeOH (50:50, $v / v)$ added with $9 \mu \mathrm{M}$ TEA. Optimal separation was achieved with mobile phase 3 . Injection volumes $20 \mu \mathrm{L}$ and $100 \mu \mathrm{L}$ were also tested but smaller injection was preferred to avoid overloading on column during analysis.

The peak responses were measured at 472 $\mathrm{nm}$ for lycopene and $450 \mathrm{~nm}$ for $\beta$-carotene with the help of a variable wavelength UV/Vis monitor coupled diode-array detector, with an output to chromatographic data handling system (Agilent ChemStation software) which permitted manual manipulation of peak integration.

The identification of the peaks was carried out by comparing the retention times with those obtained with a standard solution of all-trans lycopene (Figure 1). The quantification was performed using calibration curves made with different injected amounts of external standard, all-trans-lycopene; in a similar proportion as in the samples.

\section{Peak Identification and Quantification}

Identification of carotenoids was carried out by comparison of HPLC retention times with corresponding standards and chromatographic properties with standards of lycopene and $\beta$ carotene. Additional identification was carried out 


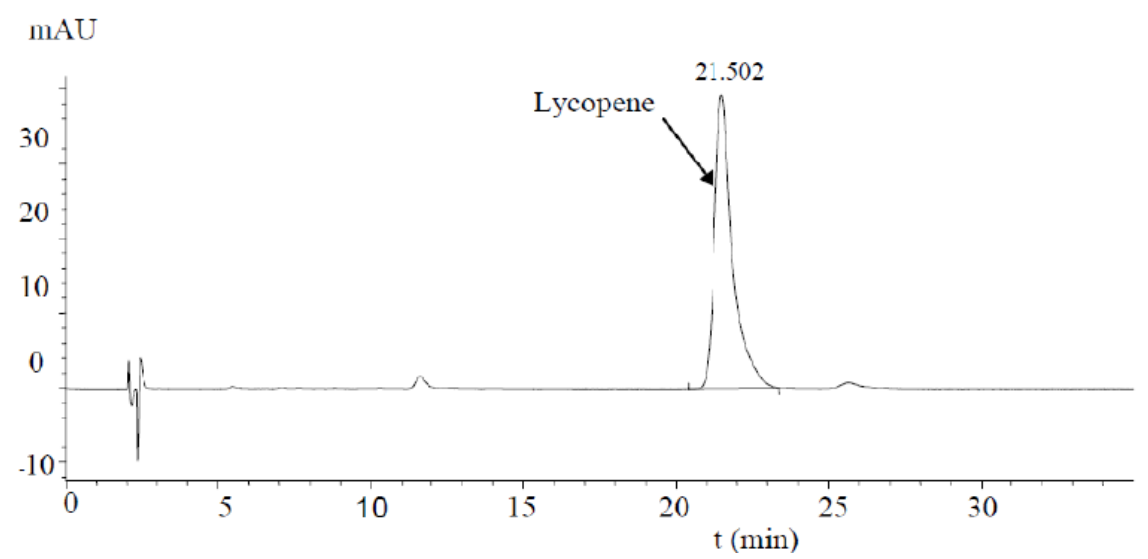

Figure 1: Chromatogram of lycopene standard solution under chromatographic condition: Prevail $\mathrm{C}_{18} 5 \mu$ $\left(250 \times 3 \mathrm{~mm}\right.$, i.d.), coupled to Prevail $\mathrm{C}_{18} 5 \mu(7.5 \times 2.1 \mathrm{~mm}$, i.d.) guard column; mobile phase $\mathrm{MeOH} / \mathrm{ACN}(50: 50, \mathrm{v} / \mathrm{v})$ added with TEA $9 \mu \mathrm{M}$; flow rate $0.6 \mathrm{ml} / \mathrm{min}$; column temperature 30 ${ }^{\circ} \mathrm{C} ; \lambda_{\text {detection }}=472 \mathrm{~nm}$.

comparing spectral data obtained with DAD array detector G1315A with reported values (Schierle et al., 2003). In general, quantitative analysis of carotenoids is carried out by external calibration curve method, generated from measurements made with many concentrations of pure standards $(0.039-2.8 \mu \mathrm{g} / \mathrm{mL})$. Then lycopene content in tomato was calculated according to formula 2 here below. Finally, the data were expressed as milligram of each carotenoid per $100 \mathrm{~g}$ fresh weight of the tomato analyzed.

$$
\text { Lycopene }[\mathrm{mg} / \mathrm{g}]=\frac{\mathrm{A}_{\mathrm{Sa}} \mathrm{V}_{\mathrm{T}} \mathrm{V}_{2}}{\mathrm{~m} \cdot \mathrm{RF} \cdot \mathrm{V}_{1}}
$$

Where, Asa: Peak areas of lycopene from sample solution [mAU], $\mathbf{m}$ : Amount of sample [g], RF: Response factor [mAU/mg], VT: Total volume of the upper lycopene bearing hexane layer $[\mathrm{mL}]$, V1: Volume of aliquot of extract, which is evaporated [mL] and V2: Volume of final sample solution [mL]

\section{In-house Validation of the Established Methods}

The established method was validated for major performance parameters (precision, accuracy, linearity, limit of detection and quantification).

Seven pointed calibration curves were constructed to test linearity within working range: $0.039-2.80 \mu \mathrm{g} / \mathrm{mL}$. This was performed six times $(n=6)$. The limit of detection (LOD) defined as amount of the carotenoid, resulting in a peak height three times the baseline noise (Hulshof et al. 1997) was calculated.

However, this concept is not practical because often time, noise level on a detector during the method development phase may be different when samples are assayed on different detectors, etc (CDER, 1994). So, for reliable quantification (LOQ) the lowest standard concentration level in the calibration range was considered as stated by www.iupac.org. Limits of quantification (LOQ) were set at 2.5 times the LOD (Hulshof et al., 1997). Based on this relation, LOD was calculated.

The accuracy of the HPLC analysis was monitored by means of a recovery assay. Fresh tomato samples were spiked with internal standard solutions of $0.055 \mathrm{mg} / \mathrm{mL} \quad \beta$-apocarotenal. The spiked samples $(n=8)$ were subjected to the entire process of extraction and HPLC analyses. The \% recovery of carotenoids, calculated below.

In order to check the precision of the method the injection repeatability, the calibration repeatability and the extraction repeatability were calculated in terms of relative standard deviations (RSD).

$$
\text { Recovery }(\%)=\frac{\text { Analyzed Amount }}{\text { Added Amount }} \times 100
$$

\section{Statistical Analysis}

All tomato data from HPLC-analysis were subjected to analysis of variance (ANOVA) to determine statistically significant differences in lycopene content between loose and cluster, and between different cultivars at $p<0.05$ using SAS/STAT® version 9.1 (SAS institute, Inc. Cary, NC, United States).

$$
\begin{gathered}
\mathrm{SEP}=\sqrt{\frac{1}{1 \mathrm{p}-1} \sum_{\mathrm{i}=1}^{1 \mathrm{p}}(\mathrm{Yi}-\mathrm{yi}-\mathrm{bias})^{2}}, \\
\text { where bias }=\frac{1}{1 \mathrm{p}} \sum_{\mathrm{i}=1}^{1 \mathrm{p}}(\mathrm{Yi}-\mathrm{yi})
\end{gathered}
$$

Where, $Y \boldsymbol{i}$ is the predicted value of the ith observation, $y \boldsymbol{i}$ is the measured value of the ith observation and $\boldsymbol{I p}$ is the number of observations in the validation. 


\section{RESULTS AND DISCUSSION}

\section{HPLC Method Development and Validation}

\section{Optimization of Method}

A wide range of series of analyses has been carried out to develop efficient and accurate methodology using HPLC for lycopene analysis in tomato starting with Barb et al. (2006) protocol. According to this protocol the best composition were: mobile phase was MeOH/ACN $(90: 10, \mathrm{v} / \mathrm{v})$ added with $9 \mu \mathrm{M}$ TEA, extraction solvent hexane/acetone/ethanol (50:25:25, v/v/v), redissolution solvent was THF/CAN/MeOH $(15: 30: 55, \quad \mathrm{v} / \mathrm{v} / \mathrm{v})$ and flow rate was 0.9 $\mathrm{mL} /$ minute. However, in this solvent combination the obtained chromatogram results (Figure 2) showed completely poor resolution, peaks were not baseline separated and also impure spectra were seen. Such different outcome might have arisen due to the difference in chromatographic apparatus such as column type and size used during our analysis and that of Barba et al. (2006).

Probably using this mobile phase composition, a balance between methanol and non-polar solvent may not be achieved due to a high Methanol $(\mathrm{MeOH})$ proportion which of course may result in great polarity difference. It has also clearly been stated that the presence of TEA has no effect on selectivity; instead it improves the response of carotenoids and reduces or eliminates on-column degradation (Hart and Scott, 1995; Rodriguez, 2001). The butylated hydroxytoluene (BHT) found in small amount $(0.025 \%)$ in THF employed in our solvents used for extraction and separation of lycopene only serves as antioxidant by controlling oxidation and isomerization reactions (Ananthanarayan and Choudhari, 2007). To our knowledge, the presence of BHT is not related with the problem of selectivity using this mobile phase. The result revels that mobile phase composition,

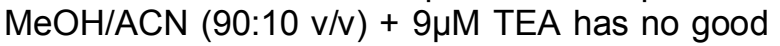
selectivity with respect to our column system and chromatographic setting.

As a result mobile phase composition, $\mathrm{MeOH} / \mathrm{ACN}(90: 10 \mathrm{v} / \mathrm{v})$ added with $9 \mu \mathrm{M}$ TEA was replaced by $\mathrm{ACN} / \mathrm{MeOH}(75: 25, \mathrm{v} / \mathrm{v})$ added with $9 \mu \mathrm{M}$ TEA, as suggested in Altech (www.alltech.be) for fat soluble vitamins keeping other procedures more or less as Barba et al. (2006). Here, chromatogram reveals that the peak of lycopene was well separated from other. However, the changed composition of mobile phase resulted in slightly extended retention time compared to the earlier composition, though not a major problem at this level of study.
At this stage the signals were well separated and broad, but with this mobile phase composition, $\mathrm{ACN} / \mathrm{MeOH}(75: 25, \mathrm{v} / \mathrm{v})$ added with $9 \mu \mathrm{M}$ TEA spectrum showed impurity (Figure 4). Different flow rates have also been tested aiming to solve spectral impurity. Finally, flow rate of 0.6 $\mathrm{mL} / \mathrm{minute}$ improved the spectral profile of lycopene when compared to other flow rates (Figure 1).

However, spectral characteristic of $\beta$-carotene was better at $0.9 \mathrm{~mL} / \mathrm{minute}$. As lycopene is the compound of interest in this study, the flow rate of $0.6 \mathrm{~mL} / \mathrm{minute}$ was further used.

The chromatographic signal presentation in Figure 3 doesn't indicates any impurity of the peak; the spectrum evaluation (Figure 4), however, identified the peak of lycopene as impure even at a flow rate $0.6 \mathrm{~mL} / \mathrm{minute}$. According to the HPLC manual (Agilent company) spectral impurities can be caused by changes in solvent composition (gradients) or in peaks that are not baseline separated. Hence, the mobile phase, ACN/ MeOH (75:25, v/v) added with TEA $9 \mu \mathrm{M}$ was changed into a new composition, ACN/ MeOH (50:50, v/v) added with TEA $9 \mu \mathrm{M}$. This new composition aimed to balance between methanol and non-polar solvents, as a high methanol proportion can cause lycopene precipitation in the extracts (Barba et al., 2006), and a high non-polar solvent content caused deformation of the chromatographic characteristic (Figure 4) due to the great polarity difference.

As clearly observed from the chromatogram and spectral characteristic (Figure 5, 6 and 7), the new mobile phase which consists of equal composition of $\mathrm{ACN}$ and $\mathrm{MeOH}$ has removed most of the defects including spectral impurity that was observed during the two previous mobile phase systems.

During optimization it was also seen that the re-dissolution solvent mixture THF/ACN/ $\mathrm{MeOH}(15: 30: 55, \mathrm{v} / \mathrm{v} / \mathrm{v})$ resulted in lycopene precipitation. The precipitation was formed at the bottom of vial even after prolonged agitation, which indicates that the desired compound cannot dissolve completely with this redissolution solvent combination affecting the recovery of lycopene when observed from the peak area obtained.

Besides, the re-dissolution solvent combination THF/ACN/MeOH (15:30:55, v/v/v) showed lack solubility for lycopene. Later when 


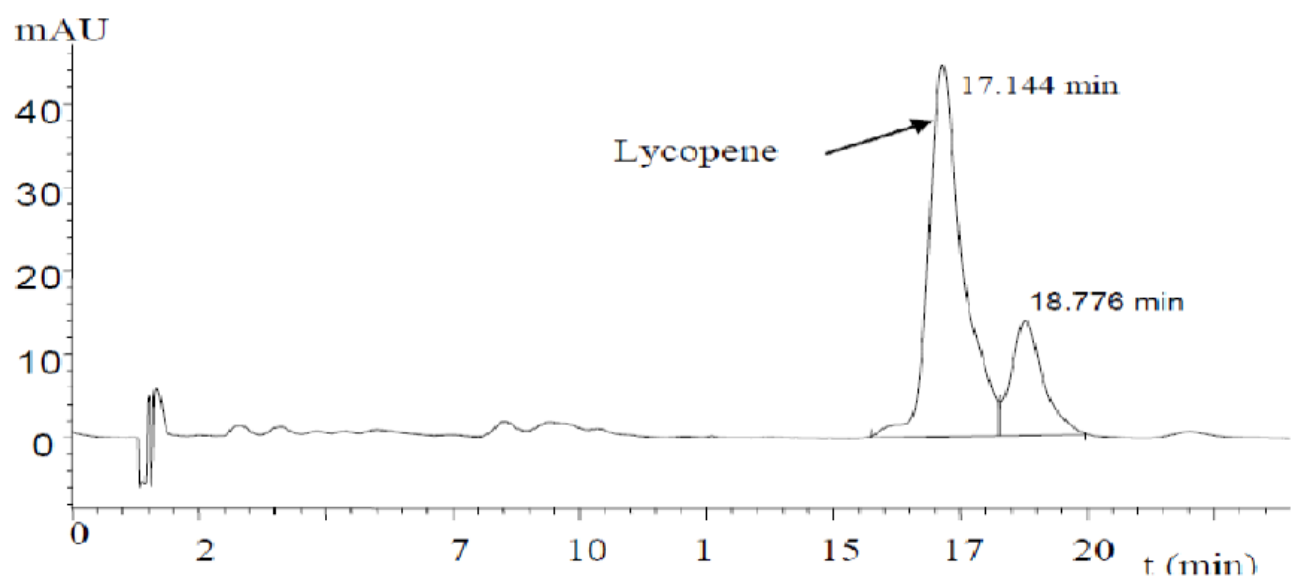

Figure 2: Chromatogram of tomato extract under chromatographic condition: Prevail $\mathrm{C}_{18} 5 \mu(250 \times 3 \mathrm{~mm}$, i.d.), coupled to Prevail $\mathrm{C}_{18} 5 \mu(7.5 \times 2.1 \mathrm{~mm}$, i.d.) guard column; mobile phase $\mathrm{MeOH} / \mathrm{ACN}$ $\left(50: 50\right.$, v/v) added with TEA $9 \mu \mathrm{M}$; flow rate $0.9 \mathrm{ml} / \mathrm{min}$; column temperature $30^{\circ} \mathrm{C} ; \lambda_{\text {detection }}=$ $472 \mathrm{~nm}$ (where y-axis shows response in $\mathrm{mAU}$ ).

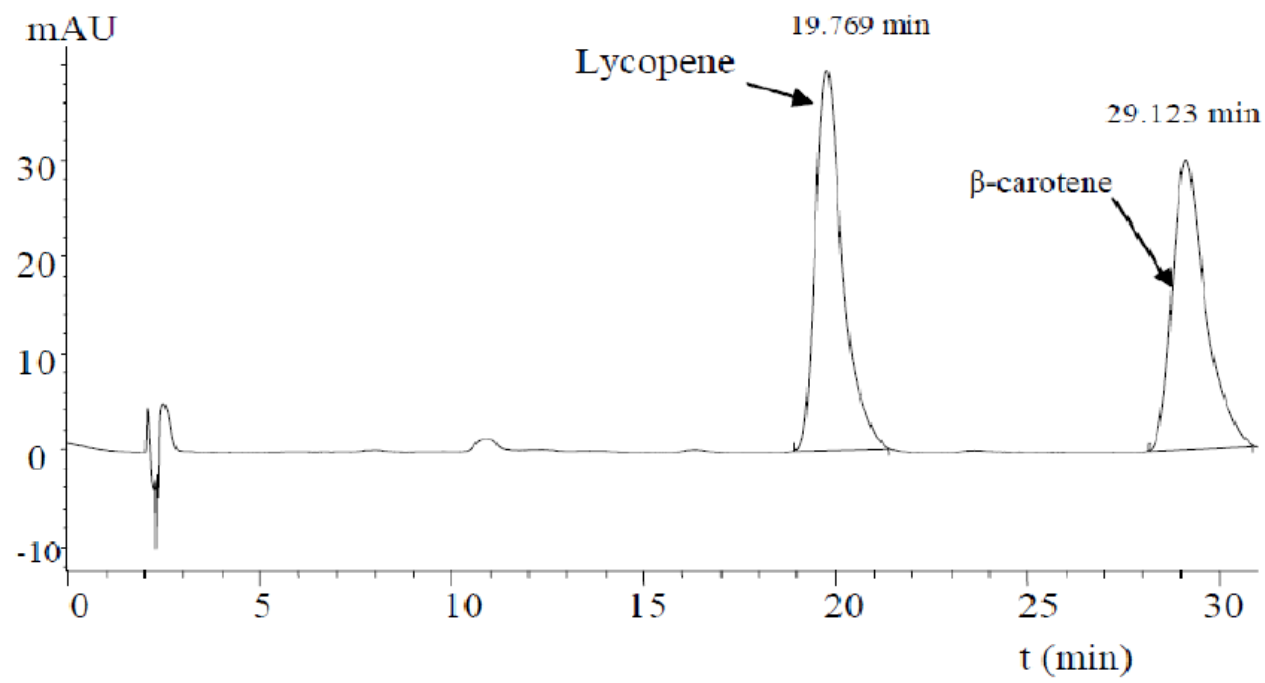

Figure 3: Chromatogram of tomato extract mixed with standards (lycopene and $\beta$-carotene) under chromatographic condition: Prevail $\mathrm{C}_{18} 5 \mu\left(250 \times 3 \mathrm{~mm}\right.$, i.d.), coupled to Prevail $\mathrm{C}_{18} 5 \mu$ (7.5x2.1mm, i.d.) guard column; mobile phase ACN/MeOH $(75: 25$, v/v) added with TEA $9 \mu \mathrm{M}$; flow rate $0.6 \mathrm{ml} / \mathrm{min}$; column temperature $30^{\circ} \mathrm{C} ; \lambda_{\text {detection }}=472 \mathrm{~nm}$ and $450 \mathrm{~nm}$ respectively.

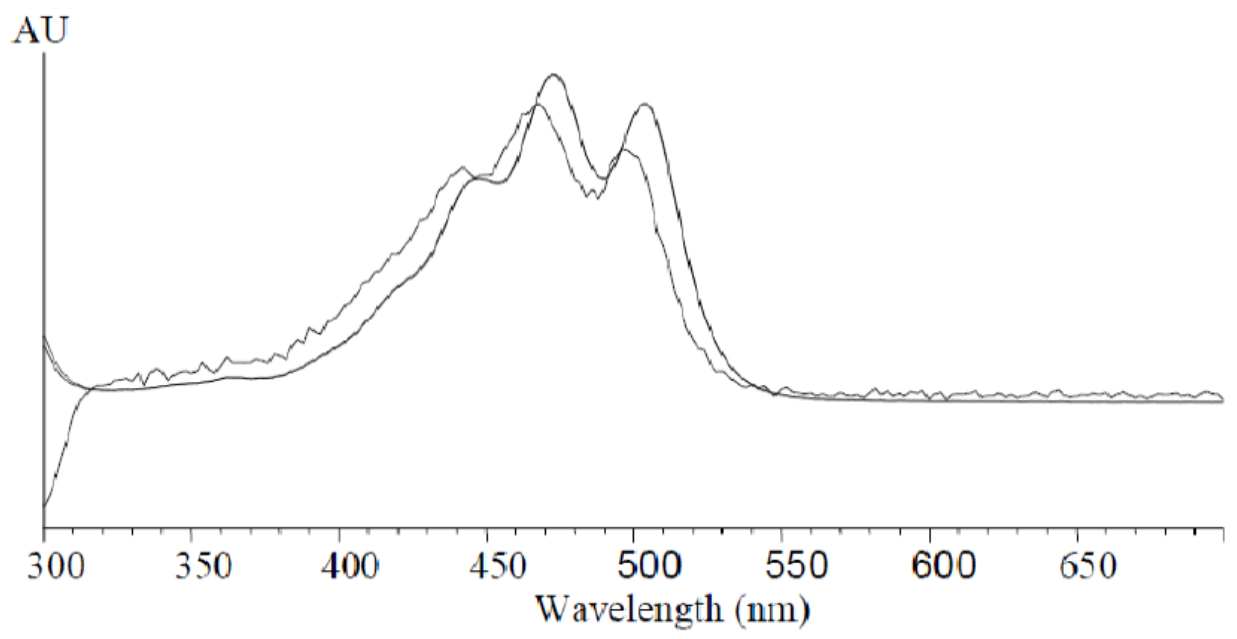

Figure 4: The UV/Vis-diode array impure spectrum (at $472 \mathrm{~nm}, 0.6 \mathrm{~mL} / \mathrm{min}$ ) of lycopene of the first peak of figure 1.3 (y-axis shows absorbance) 


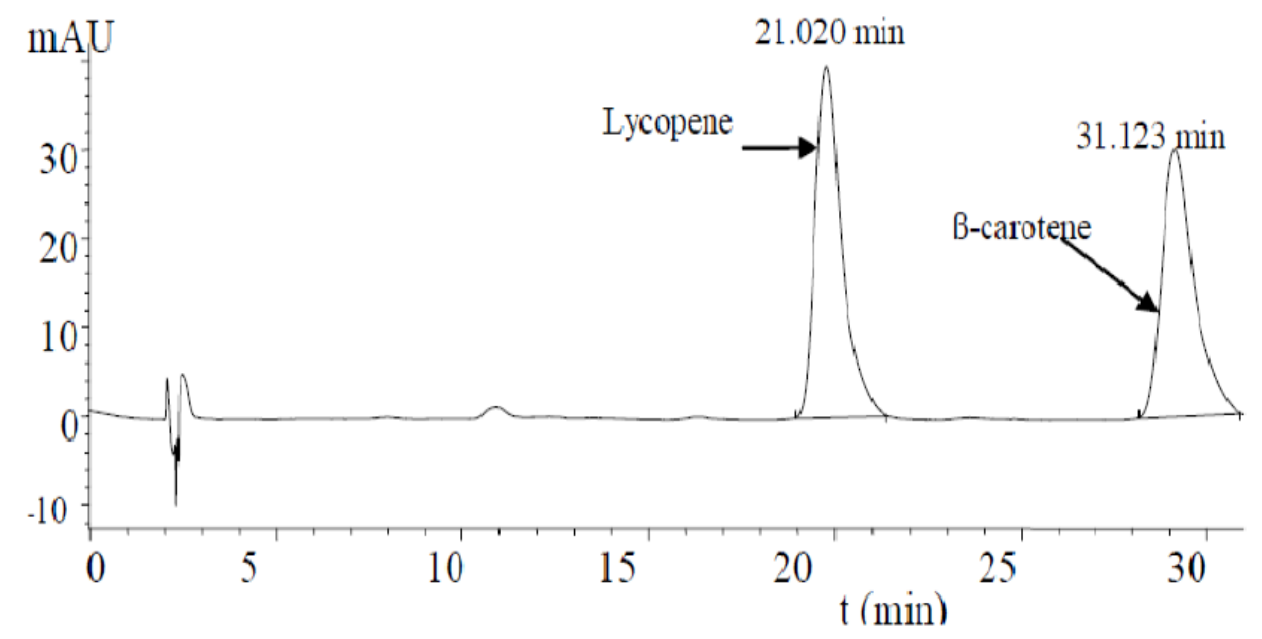

Figure 5: Chromatogram of tomato with lycopene and $\beta$-carotene under chromatographic condition: Prevail $\mathrm{C}_{18} 5 \mu\left(250 \times 3 \mathrm{~mm}\right.$, i.d.), coupled to Prevail $\mathrm{C}_{18} 5 \mu(7.5 \times 2.1 \mathrm{~mm}$, i.d.) guard column; mobile phase ACN/MeOH (50:50, v/v) added with TEA $9 \mu \mathrm{M}$; flow rate $0.6 \mathrm{ml} / \mathrm{min}$; column temperature $30^{\circ} \mathrm{C} ; \lambda_{\text {detection }}=472 \mathrm{~nm}$ and $450 \mathrm{~nm}$ respectively.

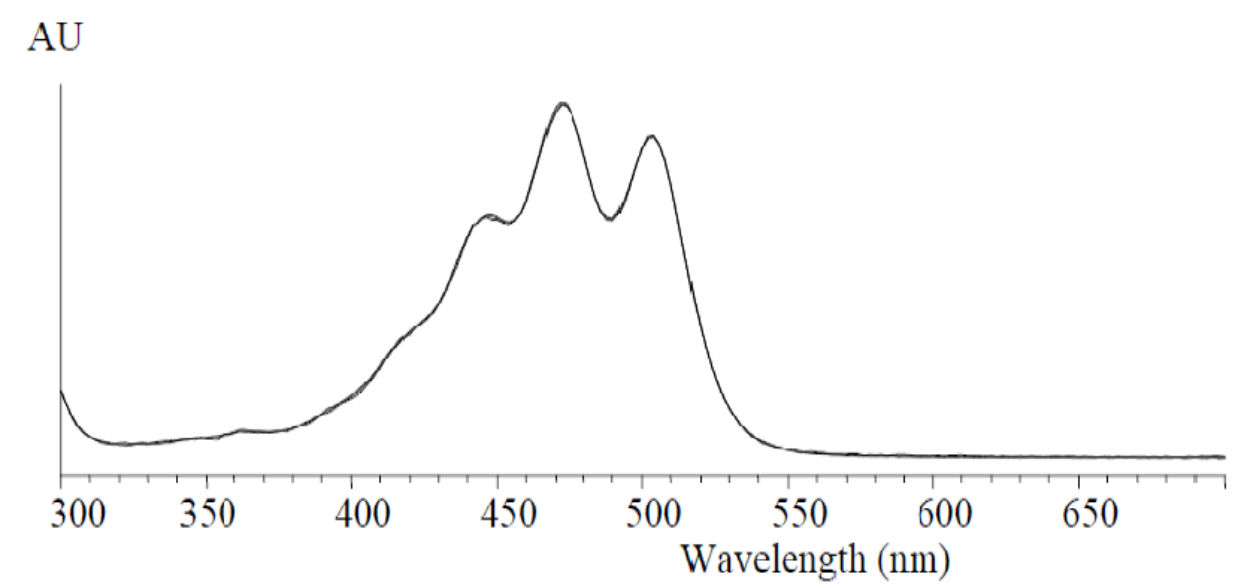

Figure 6: UV/Vis-diode array spectrum of the lycopene peak at $472 \mathrm{~nm}$ confirming spectral profile of lycopene (Qiu et al., 2006) (y-axis shows absorbance).

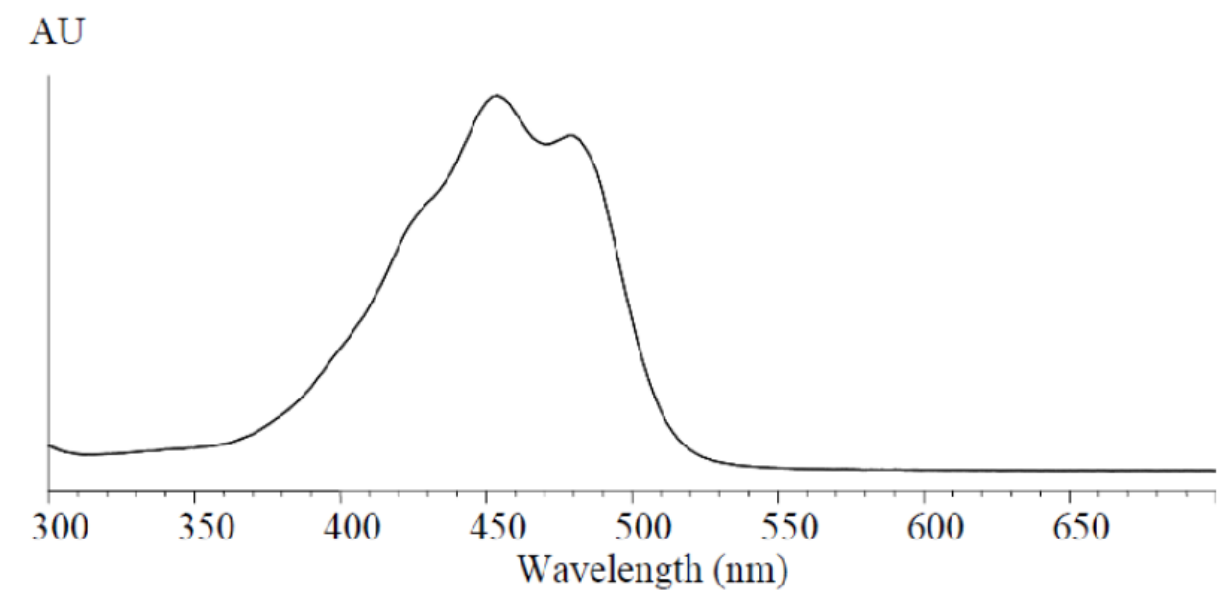

Figure 7: UV/Vis-diode array spectrum of $\beta$-carotene peak at $450 \mathrm{~nm}$. 


\section{Wondu Garoma Berra}

the solubility of the tomato lycopene standard was tested, THF was very efficient in dissolving lycopene while the solubility of lycopene in $\mathrm{MeOH}$ was very poor. The presence of $\mathrm{MeOH}$ hampered the extraction of lycopene due to the poor solubility of this compound in Methanol. Redissolving the residue first in THF followed by the remaining ( $\mathrm{ACN}$ and $\mathrm{MeOH}$ ) maintaining 15:30:55 composition was found as best combination. Although the solubility of lycopene must be ensured, filtering of the solution to establish concentrations for absorbance reading were not necessary as all the solvents used for our study were HPLC gradient grade. In all cases, extraction solvent hexane/acetone/ ethanol (50:25:25) was used without any modification.

In conclusion, the mobile phase composition ACN/MeOH (50:50, v/v) added with TEA $9 \mu \mathrm{M}$, extraction solvents hexane/acetone/ethanol $(50: 25: 25 \mathrm{v} / \mathrm{v} / \mathrm{v})$ and re-dissolving the residue in THF, followed by ACN/MeOH (15:30:55, v/v/v) at flow rate $0.6 \mathrm{~mL} / \mathrm{min}$ showed best results achieving the characteristic spectral profile of lycopene with a repeatable extraction of carotenoids in tomato in a good recovery.

\section{Validation of the Established Method \\ Linearity and Calibration Curve}

For HPLC, a series of tomato lycopene standards were dissolved in the same conditions as mentioned in the method and was injected in the chromatographic system. An external calibration curve for the tomato lycopene standard is represented graphically in the Figure 8 showing the area vs. concentration. The response of lycopene was linear between 0.039$2.8 \mu \mathrm{g} / \mathrm{mL}$ with a coefficient of determination (R2) of 0.999 . In validation guideline from Khachik et al., 1992) recommends, for validity of standards and instrumentation correlation coefficient $(r)$ of $>$ 0.9 and an intercept very close to zero. In another guideline by Mantoura et al. (1997) a correlation coefficient $(r)>0.95$ is also mentioned for validation of linearity. So based on this guidelines the linearity between 0.039 and $2.8 \mu \mathrm{g} / \mathrm{mL}$ fulfills the requirements. The relative standard deviation $(n=6)$ of the regression (calculated as standard error of the estimate divided by average concentration of the standards multiplied by 100) was about $3.2 \%$. Once again this is within the recommended range which is suggested $<5 \%$ (Khachik et al., 1992).

The limit of quantification (LOQ) was considered at the lowest standard concentration level in the calibration, was $0.039 \mu \mathrm{g} / \mathrm{mL}$. The
Sci. Technol. Arts Res. J., Oct-Dec 2012, 1(4):14-26

limit of detection (LOD), calculated as LOQ divided by 2.5 (Hulshof et al., 1997) was 0.0156 $\mu \mathrm{g} / \mathrm{mL}$.

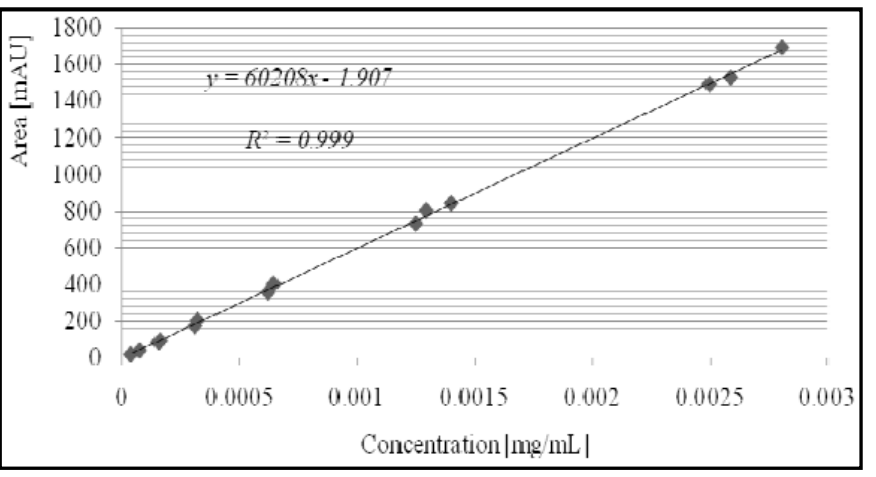

Figure 8: Seven pointed $(n=2)$ calibration curve for lycopene standard showing area vs. Concentration.

\section{Precision}

The precision of the instrumental technique $(n=10)$ was evaluated by analyzing standard samples prepared by serial dilution within the working range each day for about two weeks. In this way the repeatability calculated as standard deviation (RSD) of the slope of the calibration was $1.1 \%$. This indicates the variability observed within a laboratory, over a short time period given that all analyses were done with same items of equipments and by same operator. The repeatability of the instrument during the entire analysis was also determined as intermediate precision $(\mathrm{RSD}=2.1 \%$ ) (Table 1). A method's intermediate precision may reflect discrepancies in results obtained by different operators, from different instruments, with standards and reagents from different suppliers, with columns from different batches or a combination of these factors (www.labcompliance.com).

Table 1: Precision of the HPLC method for analysis of lycopene in tomato.

\begin{tabular}{cc}
\hline Precision & $\begin{array}{c}\text { RSD } \\
(\%)\end{array}$ \\
\hline $\begin{array}{c}\text { Injection repeatability }(n=64) \\
\text { Repeatability of slope of calibration curve } \\
\text { Response factor RSD }\end{array}$ & $<0.65$ \\
$\quad$ Short - term $(n=10)$ & 1.1 \\
$\quad$ Intermediate $(n=16)$ & 2.1 \\
Retention time RSD $(n=8)$ & 2.0 \\
Extraction repeatability $(n=32)$ & 0.53 \\
\hline
\end{tabular}

In order to check injection repeatability of method within and between run, eight tomato sample determinations within a day were assessed for about two weeks. The overall 


\section{Wondu Garoma Berra}

injection repeatability (RSD) within and between run $(n=64)$ was $<0.65 \%$, which is acceptable. As part of methods validation, a minimum of 5 injections with RSD of $\leq 1 \%$ is recommended (CDER, 1994). Injection precision expressed as RSD indicates the performance of HPLC, including plumbing, column and environmental conditions during sample analysis. It is obvious that sample preparation and manufacturing variations are not considered here.

For the whole sample extraction and instrumental analysis, the extraction repeatability were calculated as relative standard deviation $(\mathrm{RSD}=0.53 \%)$. This was obtained by performing two extractions from samples of same tomato fruits and analyzing several samples of tomato each day for about two weeks by using the established methods. Since keeping same sample to determine over the following days for tomato were considered not useful as the lycopene contents easily degrades after a short time, fresh tomato samples were examined every day.

Most of RSD values obtained in this study (Table 1) were below the limits of $15 \%$ recommended for analysis of biological samples for substances around $1 \mu \mathrm{g} / \mathrm{mL}$ recommended by AOAC (1993).

\section{Accuracy and Recovery}

The accuracy of the method and possible matrix effects of HPLC analysis were monitored by means of a recovery assay. Tomato samples were spiked with internal standard solutions of $0.05445 \mathrm{mg} / \mathrm{mL} \quad \beta$-apo-8'-carotenal. The spiked samples $(n=8)$ were subjected to the entire process of extraction and HPLC analysis. The amount of $\beta$-apo-8'-carotenal obtained after analysis was calculated relative to the amount added at the beginning using the formula indicated in the method.

Accordingly, mean recovery percentages for HPLC method ranged between $81.7 \%$ and $84.5 \%$. This value is in the interval accepted by AOAC (1993) which recommends for substances around $10 \mu \mathrm{g} / \mathrm{mL}$ recoveries between $80-110 \%$. The mean recovery of the internal standard obtained using the procedures of the established method were $83.0 \%$ (Table 2).

As the summary in Table 2 indicated, recovery percentage of the analytes obtained were found to be unaffected by the composition of the matrices. Water and tomato juice both centrifuged and un-centrifuged were analyzed. In conclusion, results of this study show that, it is
Sci. Technol. Arts Res. J., Oct-Dec 2012, 1(4):14-26

possible to use the established method for the routine analysis of carotenoids in tomato samples with a good recovery and accuracy.

\section{System Suitability Parameters}

Although system suitability specifications and tests are parameters which provide assistance in achieving accuracy and precision of the HPLC data collected, most of these parameters were not well assessed in this study. The result on injection repeatability was already presented in Table 1 which is within the maximum limit recommended by CDER (1994).

The capacity factor (a measure of where the peak of interest is located with respect to the void volume, i.e., elution time of the non-retained components) was estimated to be higher than 3.2. This indicated that our target peak was wellresolved from other peaks and void volume. The value of capacity factor $\left(k^{\prime}\right)$ should generally be higher than 2 (CDER, 1994).

\section{Application of the Method for Selected Tomato Cultivars}

The developed HPLC method was applied in screening of 10 tomato cultivars for their lycopene content. A representative chromatographic output of 2 tomato cultivars (each from cluster and loose type) are shown in Figure $9(a$ and $b)$. A summary of the results obtained from the extraction of the selected tomato cultivars are also presented in table 3 .

The identification of lycopene peak in the tomato samples was not that difficult even though the retention times showed slight fluctuation up to $2 \%$ variability calculated as RSD (Table 1 ) for all the analyses including for the standard. As far as the tomatoes analyzed in our study is concerned, there was no other carotenoid than $\beta$-carotene which appears on chromatogram result (Figure 9 ( $a$ and $b$ )) along with lycopene. Of course in tomato these are the two dominant carotenoids with lycopene representing 80-90\% (Nguyen and Schwartz 1999) and $\beta$-carotene $7-10 \%$ (Gould, 1974).

Since the time between extraction and HPLC analysis was considerably minimized, no degradation of carotenoid happened during analysis. In case of degradation we would have seen a number of peaks of cis-lycopene and cis$\beta$-carotene on the chromatogram. Therefore, comparing retention time with the corresponding pure lycopene standard and relying on the spectral characteristic was found to be sufficient for identification of lycopene from tomato samples. Actually, additional identification was 
Table 2: Recovery of $\beta$-apo-8' carotenal added to tomato sample (juice).

\begin{tabular}{|c|c|c|c|c|c|}
\hline $\begin{array}{c}\text { Analyzed and spiked } \\
\text { samples }\end{array}$ & $\mathbf{n}$ & $\begin{array}{l}\text { Initial } \\
\text { added } \\
(\mathrm{mg} / \mathrm{mL})\end{array}$ & $\begin{array}{c}\text { Area of } \\
\text { ISt* }^{*} \\
\text { Recovered }\end{array}$ & $\begin{array}{l}\text { Amount of ISt } \\
\text { Recovered } \\
\text { (mg/mL) }\end{array}$ & $\begin{array}{c}\% \\
\text { Recovery }\end{array}$ \\
\hline Tomato sample + ISt & 1 & 0.05445 & 575.2 & 0.04485 & 82.4 \\
\hline Tomato sample $+\mathrm{ISt}+\mathrm{H}_{2} \mathrm{O}$ & 2 & 0.05445 & 577.1 & 0.04498 & 82.6 \\
\hline $\begin{array}{c}\text { Tomato sample + ISt + } \\
\text { Tomato juice }\end{array}$ & 2 & 0.05445 & 578.0 & 0.04507 & 82.8 \\
\hline $\begin{array}{l}\text { Tomato sample }+ \text { ISt }+ \\
\text { Centrifuged tomato juice }\end{array}$ & 3 & 0.05445 & 587.5 & 0.04583 & 82.2 \\
\hline
\end{tabular}

Mean \% Recovery

83.0

* ISt: Internal standard ( $\beta$-apo-carotenal), amount of ISt used was $1 \mathrm{~mL}$; amount of $\mathrm{H}_{2} \mathrm{O}$ and juice spiked was $2 \mathrm{M}$.

Table 3: Lycopene content in $\mathrm{mg} / 100 \mathrm{~g}$ fresh weigh in selected tomato cultivars before and after correction for recovery.

\begin{tabular}{|c|c|c|c|c|}
\hline \multirow{3}{*}{ Tomato Types } & \multicolumn{4}{|c|}{ Lycopene content (mg/100 $\mathrm{g}$ fresh weight) } \\
\hline & \multicolumn{2}{|c|}{ Before correction } & \multicolumn{2}{|c|}{ After correction } \\
\hline & Range & Mean \pm SD & Range & Mean \pm SD \\
\hline \multicolumn{5}{|l|}{$\begin{array}{c}\text { Cluster } \\
\text { cultivars }\end{array}$} \\
\hline Tricia & $2.94-5.16$ & $4.32 \pm 0.87$ & $3.55-6.22$ & $5.20 \pm 1.05$ \\
\hline Clotilde & $4.31-5.02$ & $4.63 \pm 0.26$ & $5.20-6.05$ & $5.58 \pm 0.31$ \\
\hline Bonaparte & $4.39-6.83$ & $5.51 \pm 0.92$ & $5.28-8.23$ & $6.64 \pm 0.53$ \\
\hline Plaisance & $3.73-4.99$ & $4.17 \pm 0.44$ & $4.49-6.01$ & $5.02 \pm 0.71$ \\
\hline Dirk $\left(^{*}\right)$ & - & - & - & - \\
\hline \multicolumn{5}{|l|}{ Loose cultivars } \\
\hline Growdena & $2.47-3.65$ & $3.13 \pm 0.44$ & $2.97-4.40$ & $3.77 \pm 0.53$ \\
\hline Brodena & $1.59-3.12$ & $2.34 \pm 0.60$ & $1.91-3.76$ & $2.81 \pm 0.73$ \\
\hline DRW 75 - 93 & $2.15-3.85$ & $2.96 \pm 0.59$ & $2.59-4.64$ & $3.56 \pm 0.71$ \\
\hline Excelsior & $1.80-3.59$ & $2.67 \pm 0.59$ & $2.17-4.32$ & $3.22 \pm 0.71$ \\
\hline Admire* & - & - & - & - \\
\hline
\end{tabular}

also carried out in our study by comparing the obtained spectral data with reported data of Schierle et al. (2003).

In order to see the real mean differences in lycopene content within and between cultivars, analysis of variance (ANOVA) was performed taking into account cultivars, number of extraction and fruit number subjected to extraction and any combination of them. According to several literature (Maguer and Shi, 2000; Pol et al., 2004; Sahlin et al., 2004), the amount of lycopene in tomato varies considerably between cultivars, stage of maturity and growing conditions.

To assess the variation in lycopene content between loose and cluster tomatoes and within cultivars itself and between extractions, 4 cluster and 4 loose type cultivars were analyzed. Per cultivar four fruits were taken and two extractions per fruit were carried out. The injection run was requested in triplicate for each extraction. The ranges of lycopene content obtained in tomato samples are from 3.55 to $8.23 \mathrm{mg} / 100 \mathrm{~g}$ in cluster tomato and 1.91 to $4.64 \mathrm{mg} / 100 \mathrm{~g}$ in loose tomatoes as presented in Table 3.

The largest lycopene concentration obtained was $8.23 \mathrm{mg} / 100 \mathrm{~g}$ fresh weight in cultivar Bonaparte which is a cluster tomato type. Conversely, smallest lycopene concentration detected was $1.91 \mathrm{mg} / 100 \mathrm{~g}$ fresh weight in Brodena, a loose type tomato cultivar. The mean lycopene content values during this study ranged 

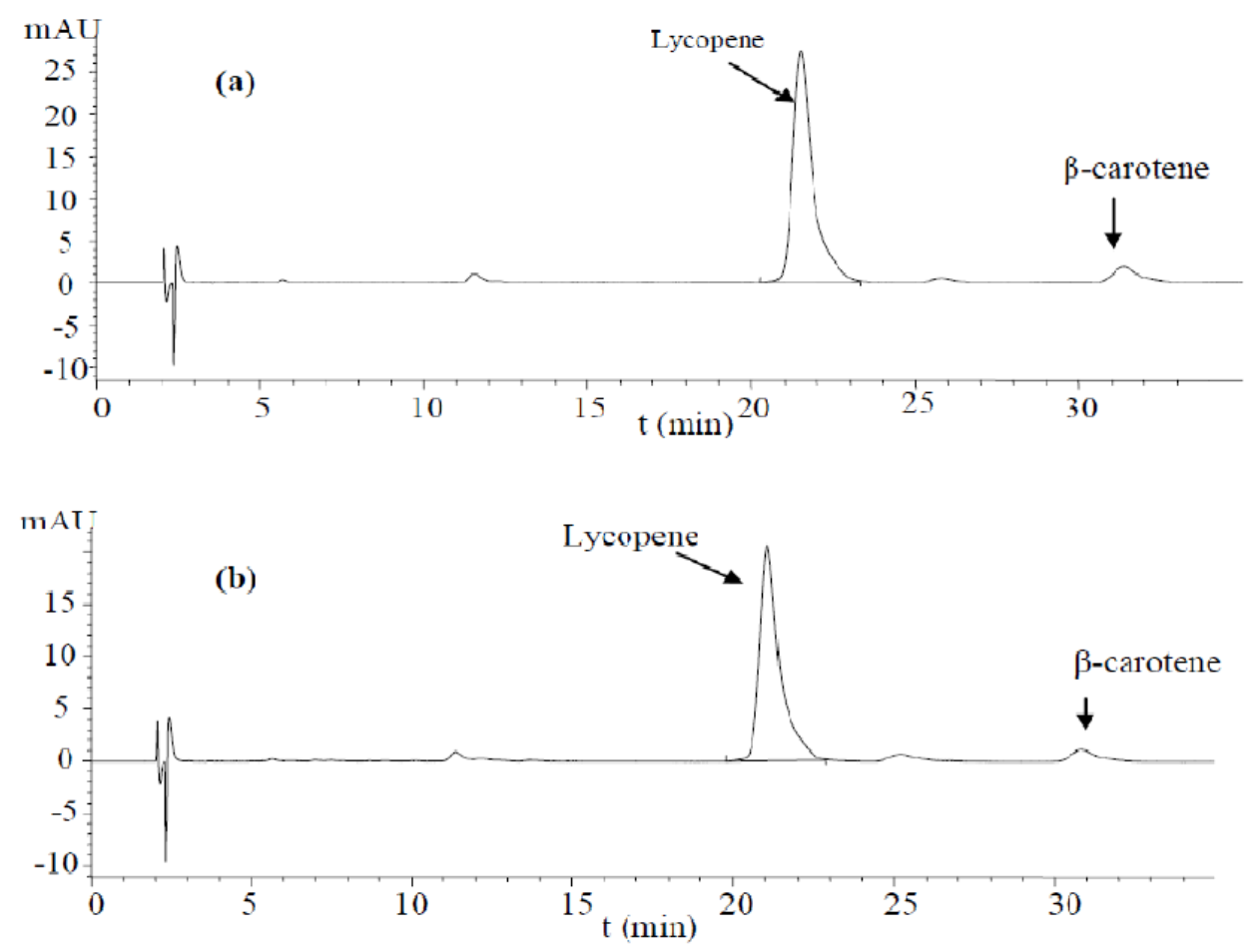

Figure 9: Carotenoids profile of tomato cultivars (a) Bonaparte (cluster type) and (b) Growdena (loose type).

from 5.02 to $6.64 \mathrm{mg} / 100 \mathrm{~g}$ fresh weight in cluster tomatoes and from 2.81 to $3.77 \mathrm{mg} / 100 \mathrm{~g}$ fresh weight in loose type. The range of composition observed in tomato cultivars analyzed in this study was in general agreement with reported values (3.1 to $7.74 \mathrm{mg} / 100 \mathrm{~g}$ fresh weight) by Nguyen and Schwartz (1999). More specifically, the average range of lycopene concentration in loose tomato exactly matches value obtained by different laboratories $(0.88$ to $4.20 \mathrm{mg} / 100 \mathrm{~g}$ fresh weight) reviewed by Roldan-Gutierrez and Castro (2007). The lycopene content for the cluster types (average value ranged up to $6.64 \mathrm{mg} / 100 \mathrm{~g}$ of fresh weight) was quite close to the literature report average value of $7.1 \mathrm{mg} / 100 \mathrm{~g}$ of fresh weight (Frusciante et al., 2007).

In general, cluster type tomatoes contained higher lycopene than loose tomaoes. The variation in lycopene concentration between cluster and loose tomatoes is up to 2-fold as clearly seen from Table 3 . This difference was not surprising due to the fact that lycopene content of tomatoes are a function of genotype, and cluster tomatoes naturally among those supposed to have high carotenoids content (George et al., 2004).

Although the number of tomato cultivars analyzed was small, our study results are also clearly outlined by statistical analysis. The mean difference in lycopene concentration between tomato cultivars, fruits, extractions and their combinations were well considered. The analysis of variance shows that there is a highly significant difference $\quad(p=0.0015)$ in lycopene content between loose and cluster tomato. The composition is significantly higher for all cluster tomatoes analyzed compared to loose types. It is interesting to point out that no statistical significant $(p=0.1680)$ interaction was observed between cultivars. This unexpected result for cultivar (type) interaction might have been attributed to the closeness in lycopene content within cultivar types. Of course, the small number of tomato cultivars (only eight) involved for statistical analyses may also have an influence.

The interaction of fruit (within cultivar and type) was highly significant $(p<0.0001)$. The ANOVA calculation also identified the interaction of extraction highly significant $(p<0.0001)$ (within cultivar, type and fruits). Consequently, the extraction system used for lycopene analysis combined with other variables can also contribute significantly to the variability obtained within same cultivar (fruit). Data of the tomato samples considered for this study confirmed that concentration of lycopene can be very different (from 1.91 to $8.23 \mathrm{mg} / 100 \mathrm{~g}$ of fresh weight) also for tomatoes having a similar intensity of red color. 
Wondu Garoma Berra

\section{CONCLUSION}

This work has provided sufficient information to the present demand of high-purity lycopene, particularly the analytical methods and careful validation procedures available for its extraction, separation, detection and preparative isolation.

Among the several HPLC conditions tested and evaluated; the mobile phase composition ACN/MeOH (50:50, v/v) added with TEA $9 \mu \mathrm{M}$, extraction solvents hexane/acetone/ethanol $(50: 25: 25 \mathrm{v} / \mathrm{v} / \mathrm{v})$ and re-dissolving the residue in THF, followed by ACN/MeOH (15:30:55, v/v/v) at flow rate $0.6 \mathrm{~mL} / \mathrm{min}$ have showed best results in achieving the characteristic spectral profile of lycopene in tomato tissue with precision and acceptable recovery.

The new analytical method provides a means for more rapid separation and quantification of the lycopene extracted from tomato. A sample can be analyzed in ca. $21 \mathrm{~min}$ without the necessity of employing a linear gradient or a gradient programme for the mobile phase. This eliminates the need to equilibrate the column between samples, which implies that no additional time is required to carry out such procedures. The two peaks, lycopene and $\beta$ carotene were well separated and identified but only lycopene was quantified in this study. The method has been evaluated against different validity parameters and applied in the screening of ten tomato cultivars for their lycopene content. The lycopene content ranged from 3.55 to 8.23 $\mathrm{mg} / 100 \mathrm{~g}$ in fresh cluster tomatoes and 1.91 to $4.64 \mathrm{mg} / 100 \mathrm{~g}$ in fresh loose tomatoes. The largest lycopene concentration, $8.23 \mathrm{mg} / 100 \mathrm{~g}$ fresh weight obtained was in cultivar Bonaparte which is a cluster tomato. Conversely, the smallest lycopene concentration, $1.91 \mathrm{mg} / 100 \mathrm{~g}$ fresh weight detected was in Brodena, a loose type tomato cultivar. To conclude, it can be said that HPLC technique is a widely accepted, efficient and accurate method of choice for the determination of lycopene in tomatoes, though sample preparation requires prolonged time.

\section{REFERENCES}

Alltech chromatography catalog 600. Alltech Associates, Inc., Brandstraat 12, B-9160 Lokeren, Belgium (www.alltech.be).

Ananthanarayan, L. and Choudhari, S.M. (2007). Enzyme aided extraction of lycopene from tomato tissues. Food Chemistry 102: 77-81.

AOAC Peer Verified methods Program (1993). Manual on policies and procedures, Arlington, V.A.
Sci. Technol. Arts Res. J., Oct-Dec 2012, 1(4):14-26

Barba, A.I.O., Ca'mara Hurtado, M., Sa'nchez Mata, M.C., Ferna'ndez Ruiz, $V$ and Lo'pez Saénza de Tejada, M. (2006). Application of a UV-vis detection -HPLC method for a rapid determination of lycopene and b-carotene in vegetables. Food Chemistry 95: 328 - 336.

Baranska, M., Schulze, W. and Schulz, H. (2006). Determination of lycopene and B-carotene content in tomato fruits and related products: Comparison of FT-Raman, and NIR spectroscopy. Analytical Chemistry 78: 8456-8461.

Berna, A. (2006). Fast instrumental techniques to analyse the aroma of tomatoes, $P h D$ Dissertationes de agricultura, Katholieke Universitiet Leuven, Belgium.

Berna, A.Z., Saevels, S., Lammertyn, J. and Nicolai, B.M. (2002). Study of system effect on the aroma profile of intact tomatoes (Lycopersicum esculentum Mill.) by means of the electronic nose. Proceedings of the 9th International Symposium on Olfaction and Electronic Nose, ISOEN'02, RomaItaly.

Barret, D.M., and Garcia, E. (2006). Assessing lycopene content in California processing tomatoes. Journal of Food Processing and Preservation 30: 56-70.

Bicanic, D., Fogliano, V., Luterotti, S., Swarts, J., Piani, G. and Graziani, G. (2005). Quantification of lycopene in tomato products: comparing the performances of a newly proposed direct photothermal method and high-performance liquid chromatography. Journal of the Science of Food and Agriculture 85: 1149-1153.

CDER, Reviewer guidance validation of Chromatographic methods (1994). Center for Drug Evaluation and Research.

DiMascio, P., Kaiser, S. and Sies, H. (1989). Archives of Biochemistry and Biophysics. 274: 532.

Frusciante, L., P. Carli, M.R., Ercolano, R., Pernice, A., DiMatteo, V., Fogliano. And Pellegrini, N. (2007). Antioxidant nutritional quality of tomato. Molecular Nutrition \& Food Research 51: 609 - 617.

George, B., Kaur, C., Khurdiya, D.S. and Kapoor, H.C. (2004). Antioxidant in tomato (Lycopersium esculentum) as a function of genotype. Food Chemistry 84: 45-51.

Gladdeny, L.F., and Alexanderz, P. (1996). Application of nuclear magnetic resonance imaging in process engineering. Measurement Science and Technology 7: 423-435.

Gomez-Romero, M., Arraez Roman, D., SeguraCarretero, A and Fernandez-Gutierrez, A. (2007). Analytical determination of antioxidants in tomato: Typical components of the Mediterranean diet. Journal of Separation Science 30: 452 - 461. 


\section{Wondu Garoma Berra}

Gould, W. (1974). Color and color measurement, in: Tomato Production, Processing and Quality Evaluation. Westport: Avi Publishing, pp. 228-244.

Hart, D.J. and Scott, K.J. (1995). Development and evaluation of an HPLC method for the analysis of carotenoids in foods, and the measurment of the carotenoid content of vegetables and fruits commonly consumed in the UK. Food Chemistry 54: $101-111$.

Hulshof, P.J.M., Xu, C., van de Bovenkamp, P. and Muhilal West, C.L.E. (1997). Application of a validated method for the determination of provitamin A carotenoids in Indonesian foods of different maturity and origin. Journal of Agricultural and Food Chemistry 45: 1174-1179.

Khachik F., Beecher, G.R., Goli, M.B. and Lusby, W.R. (1992a). Separation and quantification of carotenoids in foods. Methods Enzymology. 213:347-359.

Khachik, F., Goli, M.B., Beecher, G.R. (1992b). Effect of food preparation on qualitative and quantitative distribution of major carotenoid constituents of tomatoes and several green vegetables. Journal of Agricultural and Food Chemistry 40:390-398.

Maguer, M.L. and Shi, J. (2000). Lycopene in Tomatoes: Chemical and Physical Proporties Affected by Food Processing. Critical Reviews in Food Science and Nutrition 40(1): 1-42.

Mantoura, R.F.C., Wright, S.W. and Jeffrey, S.W. (1997). Filtration and storage of pigments from microalgae. In Jeffrey SW, Mantoura RFC, Wright SW (eds), Phytoplankton pigments in oceanography: guidelines to modern methods. UNESCO Publishing, Paris, pp 283-305

Method validation. n.d. http://www. labcompliance.com Imethods/meth_val.htm (accessed 10 10, 2007).

Nguyen, M. L., and Schwartz, S. J. (1999). Lycopene: Chemical and biological properties. Food Technology. 53 (2): 38-45.

Peirs, A., Desmet, M., Nicholai, B. and Buyssens, S. (2003). Relations between sensoy analysis, instrumental quality and NIR measurments of tomato qualiy. Edited by Oosterhhaven and H.W.Peppelenbos. Proc.8th Int.CA Conference. Acta Hort 600, ISHS, 471-477.

Pol, J., Hyotylainena, T., Ranta-Aho, O. and Riekkola, M..L. (2004). Determination of lycopene in food by
Sci. Technol. Arts Res. J., Oct-Dec 2012, 1(4):14-26

on-line SFE coupled to HPLC using a single monolithic column for trapping and separtion. Journal of Chromatography A. 1052: 25-31.

Qiu, W., Jiang, H., Wang, H. and Gao, Y. (2006). Effect of high hydrostatic pressure on lycopene stability. Food Chemistry 97:516-523.

Rao, L.G. \& Rao, A.V. (2007). Carotenoids and human health. Pharmacological Research 55:207-216.

Rolda'n-Gutie'rrez, J. M. and C. Marı'a Dolores Luque de. (2007). Lycopene: The need for better methods for characterization and determination. Trends in Analytical Chemistry 26 (2).

Rodriguez, G. A. (2001). Extraction, isolation, and purification of carotenoids. In: R. Wrolstad, T. E. Acree, H. An, E. A. Decker, M. H. Penner, D. S. Reid, S. J. Schwartz, C. F. Shoemaker, and P. Sporns (Eds.), Current protocols in food analytical chemistry (pp. F 2.1.1-F 2.1.8). New York: Wiley.

Rudnitskaya, A., Legin, A., Salles, C. and Mielle, P. (2001). Tomato varieties evaluation: electronic tongue vs. chemical analysis and sensory panel. Edited by J.R. Stetter and W.R. Penrose. Proceedings of the Artificial Chemical Sensing: Olfaction and the Electronic Nose. Sensor Division, the Electrochemical Society Inc. USA, 2001-2015.

Sahlin, E., Savage, G.P. and Lister, C.E.. (2004). Investigation of the antioxidant properties of tomatoes after processing. Journal of Food Composition and Analysis. 17: 635-647.

Schierle, J., Klipel, J.-D. and Pietch, B. (2003). Determination of added lycopene and B-carotene in foods-version 1.1. DSM Nutritional products (registered as Roche Vitamins Ltd), 12 12, 2003.

Schulz, H., Baranzka, M and Baranski, R. (2005). Potential of NIR-FT-Roman Spectroscopy in natural carotenoid analysis. Biopolymers 77: 212-221.

Xu, F., Yuan, Q.P. and Dong. H.R. (2006). Determination of lycopene and $\beta$-carotene by highperformance liquid chromatography using sudan I as internal standard. Journal of Chromatography $B$. 838: 44-49.

Yong, H., Zhang, Y., Pereira, A.G. Gomez, A. H. and Wang, J. (2005). Nondestructive determination of tomato fruit quality characteristic using Vis/NIR spectroscopy technique. International Journal of Information Technology 11(11): 97-106. 